\title{
Cellulose nanofibers produced from banana peel by chemical and mechanical treatments: Characterization and cytotoxicity assessment
}

\author{
H. Tibolla ${ }^{\text {a, }{ }^{*} \text {, F.M. Pelissari }}{ }^{\text {b }}$, J.T. Martins ${ }^{c}$, A.A. Vicente ${ }^{c}$, F.C. Menegalli ${ }^{\text {a }}$ \\ a Department of Food Engineering, School of Food Engineering, University of Campinas, Campinas, SP, Brazil \\ ${ }^{\mathrm{b}}$ Institute of Science and Technology, Food Engineering, University of Jequitinhonha and Mucuri, Diamantina, MG, Brazil \\ ${ }^{\mathrm{c}}$ CEB - Centre of Biological Engineering, University of Minho, 4710-057 Braga, Portugal
}

\section{A R T I C L E I N F O}

\section{Article history:}

Received 24 May 2017

Received in revised form

28 August 2017

Accepted 28 August 2017

Available online 31 August 2017

\section{Keywords:}

Agroindustrial waste

Unripe banana peel

Acid hydrolysis

High-pressure homogenization

Caco-2 cells

\begin{abstract}
A B S T R A C T
Cellulose nanoparticles from a vegetable source (cellulose fiber) have been evaluated for future use as reinforcement of polymeric matrixes (e.g., biodegradable films). Cellulose nanoparticles have numerous advantages: they are inexpensive and biodegradable, and they originate from renewable sources. Here, cellulose nanofibers (CNFs) were isolated from banana peel by chemical (alkaline treatment and bleaching followed by acid hydrolysis with $0.1,1$, or $\left.10 \%(\mathrm{v} / \mathrm{v}) \mathrm{H}_{2} \mathrm{SO}_{4}\right)$ and mechanical (high pressure homogenizer) treatments. Atomic Force Microscopy (AFM) analysis showed all treatments effectively isolated banana fibers at the nanometer scale (average diameter of $3.72 \mathrm{~nm}$ ). CNFs displayed $\zeta$-potential values ranging from -37.60 to $-67.37 \mathrm{mV}$, which prevented their aggregation. CNFs had high crystallinity values, from 63.1 to $66.4 \%$, which indicated they could be good reinforcing agents. FTIR results confirmed that the chemical and mechanical treatments removed the amorphous fractions. Regarding cytotoxicity, low CNF concentrations $(50-500 \mu \mathrm{g} / \mathrm{mL})$ did not cause cell death, but CNFs at concentrations above $1000 \mu \mathrm{g} / \mathrm{mL}$ significantly decreased cell viability. The use of different sulfuric acid concentrations provided more detailed knowledge of the treatment methods and CNF features, which could help to improve the CNF production process. The combination of chemical and mechanical treatments proved to be an efficient strategy to prepare CNFs from banana peels as a potential reinforcing agent of polymeric matrixes (e.g., food packaging).
\end{abstract}

() 2017 Elsevier Ltd. All rights reserved.

\section{Introduction}

In recent decades, growing environmental concern has motivated the development of sustainable processes and products. The need to develop biodegradable materials to replace synthetic products has led researchers to explore natural and renewable resources (Jiménez, Fabra, Talens, \& Chiralt, 2012). Biodegradable films employed as packaging materials can prevent moisture migration and protect food products during transport, avoiding mechanical damage and maintaining their physical integrity. Furthermore, they act as modified-atmosphere packaging that maintains the sensory characteristics of the product and prolongs its shelf life (Mali, Grossmann, \& Yamashita, 2010).

Nanometric natural fibers (cellulose source) have been explored as an alternative material to reinforce biodegradable films.

\footnotetext{
* Corresponding author.

E-mail address: heloisatibolla@gmail.com (H. Tibolla).
}

Incorporation of these nanofibers into composites offers numerous advantages, including the fact that they are biodegradable and originate from renewable sources (Pelissari, Sobral, \& Menegalli, 2014). Agricultural waste has become an attractive nanofiber source: this waste consists mainly of plant fibers that are rich in cellulose, the main component of plant cell walls (Lavoine, Desloges, Dufresne, \& Bras, 2012). Researchers have isolated cellulose nanofibers (CNFs) from the peels of fruits and vegetables such as cassava (Leite, Zanon, \& Menegalli, 2017), tomato (Jiang \& Hsieh, 2015), and potato (Chen, Lawton, Thompson, \& Liu, 2012).

Banana is one the most popular fruits worldwide, and its cultivation is widespread in tropical and subtropical regions. A wide variety of fruits, including banana, grow in Brazil because this country has the largest area of cultivable land in the world. The edible part of banana constitutes only $12 \%(\mathrm{w} / \mathrm{w})$ of the plant, and the banana peel becomes a banana processing byproduct during the production of foods like banana chips, baby foods, and unripe banana biomass. In turn, banana cultivation and industrialization generates a considerable amount of waste that is rich in 
cellulose and starch, which makes this waste a promising source of ingredients for the production of biodegradable materials (Elanthikkal, Gopalakrishnapanicker, Varghese, \& Guthrie, 2010; Pelissari et al., 2014). Pelissari, Andrade-Mahecha, Sobral, and Menegalli (2017) suggested the integral use of banana fruit: these authors used the banana pulp and peel to obtain starch and CNFs that served as film matrix and reinforcing agent, respectively.

CNF isolation from lignocellulosic materials usually involves three steps: (1) pretreatment, (2) partial hydrolysis, and (3) mechanical disintegration of the raw material (Sun, Sun, Zhao, \& Sun, 2004). Acid hydrolysis is a technology that has long industrial history and which is traditionally used to break cellulose microfibers into nanofibers (Yu, Lou, \& Wu, 2008). This process commonly employs sulfuric or hydrochloric acid because these highly aggressive acids are essential to cleave the glycosidic bonds between the cellulose chains (Pirani \& Hashaikeh, 2013). According to Chen et al. (2011), it is preferable to use sulfuric acid $\left(\mathrm{H}_{2} \mathrm{SO}_{4}\right)$ because it generates a more stable nanofiber aqueous suspension: the sulfate groups provide the nanofiber with a negatively charged surface (Saito et al., 2009), thereby preventing CNF agglomeration.

The wide application of nanotechnology has improved the characteristics of materials and generated new commercial products, but it has also increased human exposure to nanomaterials. Although nanoparticles have beneficial effects, they may endanger the human health, so possible risks should be evaluated (Jones \& Grainger, 2009). The small size, the chemical and physical properties, and the high reactivity of nanoparticles may cause them to be cytotoxic (Pereira et al., 2013). Because nanoparticles incorporated into films used as food packaging may migrate and consequently be ingested by humans, toxicological analysis is an essential part of CNF characterization. In vitro methods are currently employed for toxicological evaluation of nanomaterials. Human epithelial cells are commonly used in in vitro cytotoxicity experiments because they resemble the epithelial phenotype in vivo, including the presence of mucin coating the cell membrane, microvilli, desmosomes, and lamellar body. Caco-2 cells, which originate from human colon adenocarcinoma and are similar to the small intestinal epithelial layer, is gaining prominence in in vitro assays. In vitro permeability studies have employed Caco-2 cells to assess the cytotoxicity and the potential effect of delivery systems in terms of enhanced drug permeation (Antunes, Andrade, Araujo, Ferreira, \& Sarmento, 2013; Araújo \& Sarmento, 2013; Jones \& Grainger, 2009). Ma et al. (2013) studied lactoferrin nanoliposome anticancer efficiency by assessing Caco-2 cell viability, to find out that such nanoliposomes are a potential therapeutic modality in tumor management. Dong, Hirani, Colacino, Lee, and Roman (2012) tested the cytotoxicity of cellulose nanocrystals prepared from wood pulp fibers exposed to different cell lines representing the epithelia cells of different human organs. After $48 \mathrm{~h}$ of exposure, the cellulose nanocrystals at concentrations of up to $50 \mu \mathrm{g} / \mathrm{mL}$ were not cytotoxic to any of the investigated cell lines.

Previous studies reported by Pelissari et al. (2014) have shown that CNFs obtained by acid hydrolysis have potential application as reinforcing agents in composites. However, acid hydrolysis efficiency depends on factors like the acid concentrations. This study aimed to characterize CNFs isolated from an agro-industrial waste (unripe banana peel) by chemical treatment at different $\mathrm{H}_{2} \mathrm{SO}_{4}$ concentrations, followed by mechanical treatment (highpressure homogenizer). Moreover, an evaluation on how the CNFs affected Caco-2 cell viability was conducted, which constituted the innovative character of this scientific study.

\section{Materials and methods}

\subsection{Materials}

Banana fruit, from the variety "Terra" (Musa paradisiaca), was obtained from the southeastern region of Brazil, and no postharvest treatment was applied. All the chemicals used in this work were reagent grade. To evaluate CNF cytotoxicity, Caco- 2 cells obtained from the American Type Culture Collection (ATCC) and kindly provided by Professor Bruno Sarmento, Instituto Superior de Ciências da Saúde - Norte (Portugal) were employed. Cell cultures were purchased from Gibco ${ }^{\mathrm{TM}}$ Invitrogen, Sigma, and Lonza.

\subsection{Bran preparation}

The bran was prepared from unripe banana peels (mature green) according to the methodology described by Pelissari et al. (2014). The banana peels were manually removed and immediately immersed in potassium metabisulfite solution $(1 \% \mathrm{w} / \mathrm{v})$ for $24 \mathrm{~h}$, to inhibit oxidation. The peels were dried in a forced air convection oven at $60^{\circ} \mathrm{C}$ for $24 \mathrm{~h}$. The dried peels were ground in a knife mill (Marconi brand, mode IMA 340, SP-Brazil), and the resulting material was washed with ethanol, to remove lipid fractions, and dried in an oven at $60^{\circ} \mathrm{C}$ for $24 \mathrm{~h}$. The bran was sieved through a 200 -mesh sieve, which provided $24.5-\mu \mathrm{m}$ microparticles. The banana peel bran had the following chemical composition ( $\mathrm{g} /$ $100 \mathrm{~g}$ on dry basis): $5.2 \%$ of moisture, $9.8 \%$ of ash, $12.1 \%$ of cellulose, $10.2 \%$ of hemicellulose, and $2.9 \%$ of lignin.

\subsection{Cellulose nanofiber isolation - chemical and mechanical treatments}

Fig. 1 describes the chemical and mechanical procedures used to isolate CNFs from the banana peel bran. Acid hydrolysis was performed according to the method described by Pelissari et al. (2014), with some modifications. First, the bran was submitted to chemical treatment to eliminate non-cellulosic components. Then, the bran was treated with $5 \%(\mathrm{w} / \mathrm{v}) \mathrm{KOH}$ solution (ratio of $1: 20)$ under mechanical stirring at room temperature for $14 \mathrm{~h}$ to solubilize the pectin and hemicellulose fractions. The insoluble residue was delignified with $1 \%(\mathrm{w} / \mathrm{v}) \mathrm{NaClO}_{2}$ at $\mathrm{pH} 5.0$ (adjusted with $10 \%(\mathrm{v} / \mathrm{v}$ ) acetic acid) at $70{ }^{\circ} \mathrm{C}$ for $1 \mathrm{~h}$. This step was carried out twice to ensure that the phenolic compounds or molecules displaying chromophoric groups were effectively broken down. The insoluble residue was subjected to acid hydrolysis with different $\mathrm{H}_{2} \mathrm{SO}_{4}$ concentrations: $0.1,1$, and $10 \%(\mathrm{v} / \mathrm{v})$. The reaction was conducted at $80^{\circ} \mathrm{C}$ for $1 \mathrm{~h}$, to remove mineral traces and to hydrolyze amorphous cellulose, which afforded only the required nanofibers. Next, the mixture was cooled in an ice bath and subjected to successive washings with deionized water, until the pulp reached neutrality ( $\mathrm{pH}$ 7.0). After each chemical treatment step, the insoluble residue was neutralized with alkaline $(5 \% \mathrm{KOH})$ or acid solution $(10 \%$ acetic acid), depending on the $\mathrm{pH}$. Then, it was extensively washed with deionized water and centrifuged (10,000 rpm; $\left.5{ }^{\circ} \mathrm{C} ; 20 \mathrm{~min}\right)$. This step was repeated until neutral $\mathrm{pH}$ was reached.

The colloidal suspensions were submitted to mechanical treatment in a two-stage high-pressure homogenizer (GEA Niro Soavi, model NS 1001L - Panda 2 K, Parma, Italy). The pressure in the first and second stages was 500 and 50 bar, respectively. Aliquots of the suspension were passed through the homogenizer five times, as defined by the performed preliminary tests (Andrade-Mahecha, Pelissari, Tapia-Blácido, \& Menegalli, 2015; Pelissari et al., 2014). Finally, the resulting colloidal suspensions were diluted in deionized 


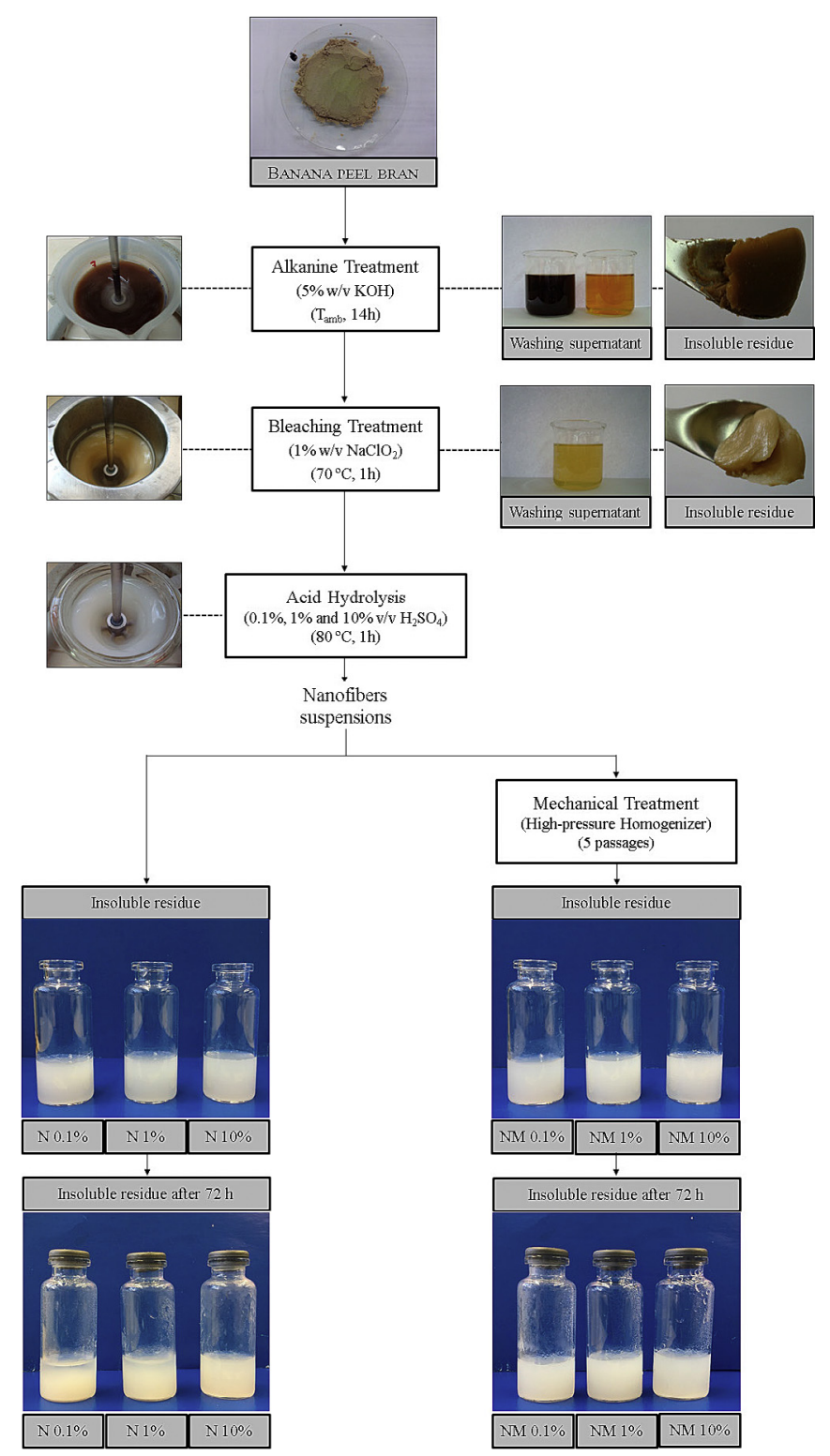

Fig. 1. Scheme describing the chemical and mechanical procedures used to isolate cellulose nanofibers from banana peel bran.

water and stored at $4{ }^{\circ} \mathrm{C}$ in sealed vessels. The CNFs obtained by mechanical treatment were labeled as NM (NM $0.1 \%$, NM $1 \%$, and NM $10 \%)(\% \mathrm{v} / \mathrm{v})$, and the CNFs that were not submitted to mechanical treatment were labeled as $\mathrm{N}(\mathrm{N} 0.1 \%, \mathrm{~N} 1 \%$, and $\mathrm{N} 10 \%)(\% \mathrm{v} / \mathrm{v})$.

\subsection{Cellulose nanofiber characterization}

\subsubsection{Scanning electron microscopy (SEM)}

The bran microstructure was analyzed by SEM. The sample was fixed on aluminum stubs with double-sided tape and coated with a gold layer (Sputter Coater Polaron, model SCD050), to improve conductivity. The coated samples were viewed under a scanning electron microscope (JEOL, model JSM-5800LV, Tokyo, Japan) operating at an acceleration voltage of $10 \mathrm{kV}$.

\subsubsection{Transmission electron microscopy (TEM)}

The structural and morphological analyses of the CNF suspensions were performed by microscopy methods. For TEM analysis, the CNF suspension was placed under ultrasound (Unique, model USC-1400A) for $5 \mathrm{~min}$, to separate the agglomerated fibers. A drop of the suspension was placed on a carbon and parlodion (300 mesh) microgrid and left to rest for $60 \mathrm{~s}$. Then, the microgrid was washed twice with deionized water $(3 \mu \mathrm{L})$, which was followed by deposition of $3 \mu \mathrm{L}$ of uranyl acetate $2 \%(\mathrm{v} / \mathrm{v})$ on the microgrid for $30 \mathrm{~s}$. The TEM images were obtained with a transmission electron microscope TEM-MSC (JEOL 2100) equipped with a LaB6 electron gun, at an accelerating voltage of $200 \mathrm{kV}$. The TEM analyses were accomplished at the Laboratory of Electron Microscopy (LME) of the National Nanotechnology Laboratory (LNNano) (Campinas, Brazil).

\subsubsection{Atomic force microscopy (AFM)}

Topography, electric potential, and capacitance gradient $(\mathrm{dC} / \mathrm{dz})$ images of the CNFs were recorded with the Nx-10 Atomic Force Microscope (Park systems, Suwon, Korea). For the analysis, $1.5 \mu \mathrm{L}$ of the CNF suspension was placed on a grid with mica surface and dried at room temperature. The digital images were acquired with a microscope equipped with a camera, under controlled parameters (relative humidity $\leq 10 \% \mathrm{RH}$ and temperature $=25^{\circ} \mathrm{C}$ ). The electric potential and the capacitance were measured (Kelvin probe force microscopy - KPFM) according to the procedures described by Ferreira et al. (2015), by applying a second AC signal at $5 \mathrm{~V}$ to the metal-coated cantilever. The $\mathrm{dC} / \mathrm{dZ}$ signal is a qualitative measure that is acquired with the third locking (signal amplitude) tuned in the second harmonic of the electric signal (AC) applied to the probe. The AFM analyses were conducted at the Laboratory for Surface Science (LCS) of the National Nanotechnology Laboratory (LNNano) (Campinas, Brazil). The nanofiber morphology and diameter were determined by image analysis with the aid of the Gwiddion software.

\subsubsection{Dynamic light scattering (DLS) measurements}

The DLS measurements were performed with a Zetasizer (Malvern Instruments Ltd., Zetasizer Nano Series-model Nano ZS, Worcestershire, England) to determine the surface charge ( $\zeta$-potential) and to estimate the CNF length in aqueous suspension, at room temperature $\left(25^{\circ} \mathrm{C}\right)$. All the experiments were done in triplicate, and the results are presented as mean values.

\subsubsection{CNF yield after acid hydrolysis}

The yield of CNFs obtained by acid hydrolysis was determined in triplicate. The CNF suspensions were previously homogenized by mechanical stirring for $30 \mathrm{~min}$. Then, $2 \mathrm{~g}$ of each sample was dried at $105{ }^{\circ} \mathrm{C}$ for $24 \mathrm{~h}$. The yield was calculated from the difference between the initial bran mass and the final bran mass (on dry basis) of the bran. The yield was determined by using Equation (1):

Yield $(\%)=\frac{g \text { of nanofiber }(\text { d.b })}{g \text { of bran }(\text { d.b })} \times 100$

\subsubsection{X-ray diffraction (XRD)}

Sample crystallinity was determined by XRD according to Van Soest, Hulleman, de Wit, and Vliegenthart (1996). An amount of each suspension (alkaline treatment suspension and CNFs suspension) was dried in a freeze-drier (Equipament Terroni, model LS 3000, São Paulo, Brazil). The freeze-dried samples were stored at $4{ }^{\circ} \mathrm{C}$ in sealed containers until XRD analysis. An X-ray diffractometer (Siemens, model D5005, Baden-Wurttemberg, Germany) operating at $40 \mathrm{kV}$ and $30 \mathrm{~mA}$ was employed. The bran and CNF crystallinity index $\left(\mathrm{I}_{\mathrm{Cr}}, \%\right)$ was calculated by using Equation (2), following the method proposed by Segal, Creely, Martin, and Conrad (1959). In this method, $\mathrm{I}_{\mathrm{Cr}}$ was calculated as the ratio of 
heights between the maximum intensity of the crystalline peak located at $2 \theta=22-24^{\circ}\left(\mathrm{I}_{200}\right)$ and the intensity of the non-crystalline diffraction at $2 \theta=18^{\circ}$ ( $\left.\mathrm{I}_{\text {non-cr }}\right)$ material.

$\mathrm{Ic}_{\mathrm{r}}=\frac{I_{200}-I_{\text {non-cr }}}{I_{200}} \times 100$

\subsubsection{Fourier-transform infrared spectroscopy (FTIR)}

The functional groups of bran, alkaline-treated bran, and freezedried CNF samples were analyzed by absorption spectroscopy in the infrared region between 4000 and $650 \mathrm{~cm}^{-1}$ with a resolution of $4 \mathrm{~cm}^{-1}$ and 20 scans (Vicentini, Dupuy, Leitzelman, Cereda, \& Sobral, 2005). An infrared Fourier-transform spectrometer (Perkin Elmer, model Spectrum One, Ohio, USA) equipped with a universal attenuator total reflectance (UATR) accessory was used.

\subsubsection{Cellulose nanofiber cytotoxicity}

The human colon carcinoma Caco- 2 cell line was used at passages 22-29. Caco-2 cells were grown in culture flasks containing Dulbecco's Modified Eagle Medium (DMEM) supplemented with $10 \%(\mathrm{v} / \mathrm{v})$ heat-inactivated fetal bovine serum, $1 \%(\mathrm{v} / \mathrm{v})$ L-glutamine, $1 \%(\mathrm{v} / \mathrm{v})$ non-essential amino acids, and $1 \%(\mathrm{v} / \mathrm{v})$ penicillinstreptomyci, and incubated at $37{ }^{\circ} \mathrm{C}$ in $5 \% \mathrm{CO}_{2}$ water-saturated atmosphere. The CNF effect on cell viability was measured by the methylthiazolyldiphenyl-tetrazolium bromide (MTT) conversion assay. CNFs were prepared at selected concentrations $(50,100,500$, 1000,2000 and $5000 \mu \mathrm{g} / \mathrm{mL}$ ) by suspending the CNFs in a supplemented DMEM medium followed by homogenization. The suspended Caco- 2 cells were seeded in a 96-well microplate (at $2.5 \times 10^{5}$ cells $/ \mathrm{mL}$ ) in $200 \mu \mathrm{L}$ of supplemented DMEM and incubated for at $37^{\circ} \mathrm{C}$ in $5 \% \mathrm{CO}_{2}$ atmosphere for $24 \mathrm{~h}$. Then, the medium was removed, and the CNF test solutions were added to the cell culture and incubated $\left(37{ }^{\circ} \mathrm{C}\right.$ in $\left.5 \% \mathrm{CO}_{2}\right)$ for $24 \mathrm{~h}$. A blank sample (DMEM without cells) and a positive control sample (DMEM with cells) were also tested. Each treatment was assayed in quadruplicate. Next, the supernatant was removed, and $200 \mu \mathrm{L}$ of MTT solution $(0.5 \mathrm{mg} / \mathrm{mL}$ in supplemented DMEM) was added to each well, protected from the light, and incubated at $37{ }^{\circ} \mathrm{C}$ for $4 \mathrm{~h}$, to allow purple formazan crystals to form. After that, the medium was removed, and the purple formazan crystals were solubilized in $200 \mu \mathrm{L}$ of DMSO. The culture plates were shaken on an orbital shaker for $30 \mathrm{~min}$ to solubilize the purple formazan crystals completely. The enzymatic reduction of yellow tetrazolium MTT to purple formazan was measured with a Synergy ${ }^{\mathrm{TM}}$ HT Multi-mode Microplate Reader (Biotek Instruments, Winooski, VT, USA) at $570 \mathrm{~nm}$. The measurement at $690 \mathrm{~nm}$ was used for background subtraction. The cell viability percentage was calculated by means of Equation (3).

$$
\text { Cell viability }(\%)=\frac{A_{\text {Exp }}-A_{\text {control }}}{A_{\text {Positive }}-A_{\text {control }}} \times 100
$$

where $A_{\text {exp }}$ is the value of the experiment $\mathrm{CNF}(\mathrm{CNF}$ solution + cell) sample test absorbance; $A_{\text {control }}$ is the value of the blank (DMEM without cells) sample absorbance; and $A_{\text {positive }}$ is the value of the positive control (DMEM + cells) absorbance.

\subsection{Statistical analyses}

The statistical analyses were performed, and the values obtained for the properties of the CNFs submitted to chemical and mechanical treatments are presented as the mean value \pm standard deviation from a minimum of three independent experiments.
One-way analysis of variance (ANOVA) and Tukey test of multiple comparisons with a significance level of $5 \%(p \leq 0.05)$ were run with the Statistic software (StatSoft Inc, Tulsa, Oklahoma, USA).

\section{Results and discussion}

\subsection{Cellulose nanofiber characterization}

The purpose of the initial alkaline and bleaching treatments was to remove lignin from the middle lamellae (i.e., the region between plant fibers which is rich in lignin), to separate the cellulose fibers (Andrade-Mahecha et al., 2015). Along these first steps of the chemical treatment that was used to isolate CNFs from the banana peel (Fig. 1), the material changed from dark brown to pale brown. Chromogen groups (such as conjugated carbonyls, double bonds, and their combination), which underlie the brown color of the initial lignocellulosic material, underwent ionization (Viikari, Kantelinen, Sundquist, \& Linko, 1994). Also, hydrolysis of constituents like starch, pectin, and hemicelluloses occurred (Dufresne, Cavaille, \& Vignon, 1997; Pelissari et al., 2014). The FTIR analysis results (Table 2) reinforced the change in color and confirmed that the chemical structure of the bran components was altered along the chemical treatment (alkaline treatment followed by bleaching and acid hydrolysis).

The bleaching process conducted after the alkaline treatment step contributed to modifying the sample color to pale brown because it removed lignin and tannins. During bleaching, chlorine and chlorites rapidly oxidized lignin, generating hydroxyl, carbonyl, and carboxylic groups. These groups facilitated lignin solubilization in alkaline medium as well as cellulose purification (Dufresne \& Vignon, 1998). Fig. 2 shows the final appearance of the CNFs in suspension after the chemical treatment. A white material emerged at the end of the process, irrespective of the acid concentration. After $72 \mathrm{~h}$ storage $\left(4^{\circ} \mathrm{C}\right)$, the physical and colloidal aspects of the suspensions changed. Compared to suspensions NM 0.1\% (v/v), NM $1 \%(\mathrm{v} / \mathrm{v})$, and NM $10 \%(\mathrm{v} / \mathrm{v})$, which underwent mechanical treatment, suspensions N 0.1\% (v/v), N 1\% (v/v), and N 10\% (v/v) (obtained without mechanical treatment) presented phase separation. Therefore, mechanical treatment favored homogeneous suspensions.

The SEM micrographs of the banana peel bran (Fig. 3) provided an insight into the fiber structure. The bran had irregular surface and contained some residues of the grinding step. The microstructure also contained starch granules as a result of the contact between the peel and the banana pulp (see arrows in Fig. 3).

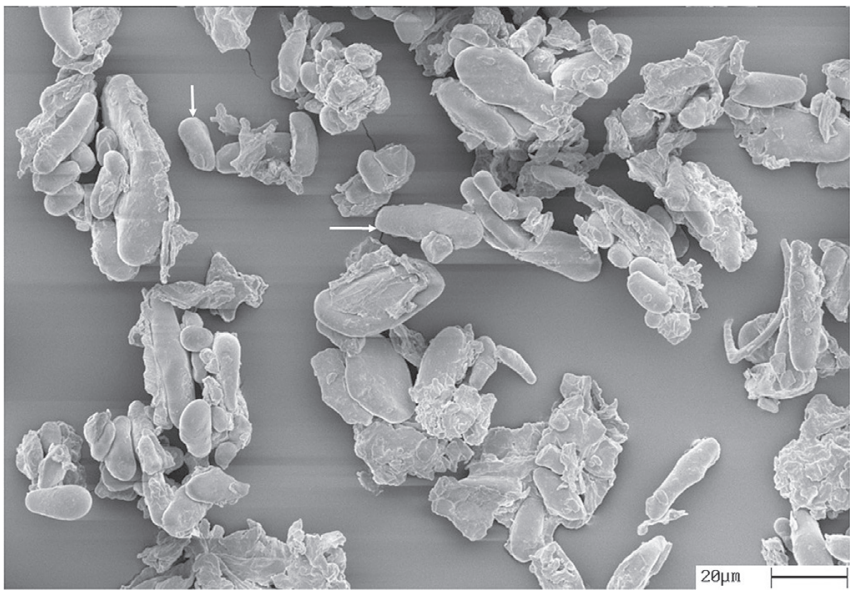

Fig. 2. SEM images of the untreated banana peel bran $(1400 \times$, scale bar $=20 \mu \mathrm{m})$ 


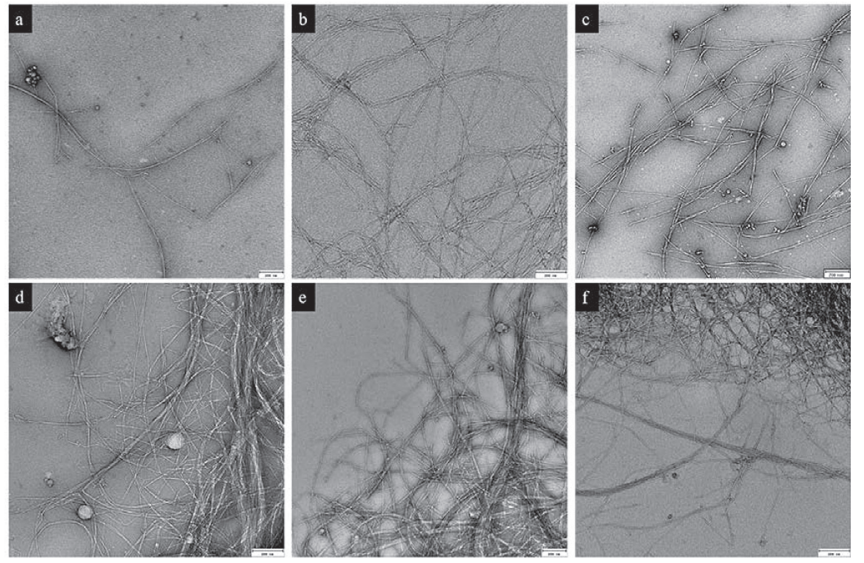

Fig. 3. TEM images of the CNFs produced by chemical hydrolysis with or without mechanical treatment: a) N $0.1 \%$, b) N $1 \%$, c) N $10 \%$, d) NM $0.1 \%$, e) NM $1 \%$ and f) NM $10 \%$ (scale bar $=200 \mathrm{~nm}$ ).

Comparison of the SEM images with the TEM and AFM images (Figs. 3-5, respectively) revealed that the fibers experienced morphological changes along the chemical treatment steps, and that CNFs were present in the six aqueous suspensions. In addition, the SEM (Fig. 3) and TEM (Fig. 4) micrographs suggested gradual removal of amorphous components such as hemicelluloses, lignin, and pectin. The images also showed that a cellulose portion remained after acid hydrolysis. Andrade-Mahecha et al. (2015) also observed this effect when they isolated CNFs from achira by chemical treatment as demonstrated by SEM and TEM images. Quantitative results obtained from the XRD analysis (mentioned below) reinforced the SEM and TEM analyses and demonstrated that the crystalline area increased along the chemical and mechanical treatments.

The TEM (Fig. 4) and AFM (Fig. 5) images confirmed the presence of CNFs in the six aqueous suspensions and indicated that the CNFs had a web-like network structure with long entangled cellulosic filaments. Leite et al. (2017) noticed CNFs with similar
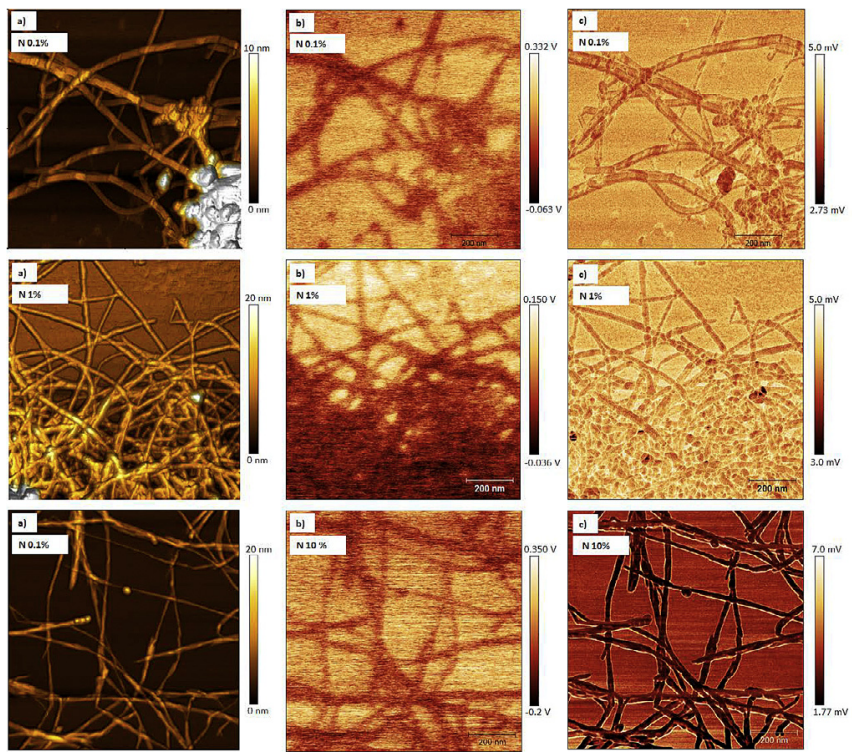

Fig. 4. AFM images from cellulose nanofibers obtained by acid hydrolysis without mechanical treatment: (a) topography, (b) electric potential and (c) dC/dz (scanning area $1.0 \mu \mathrm{m} \times 1.0 \mu \mathrm{m}$, scale bar $=200 \mathrm{~nm}$ ).
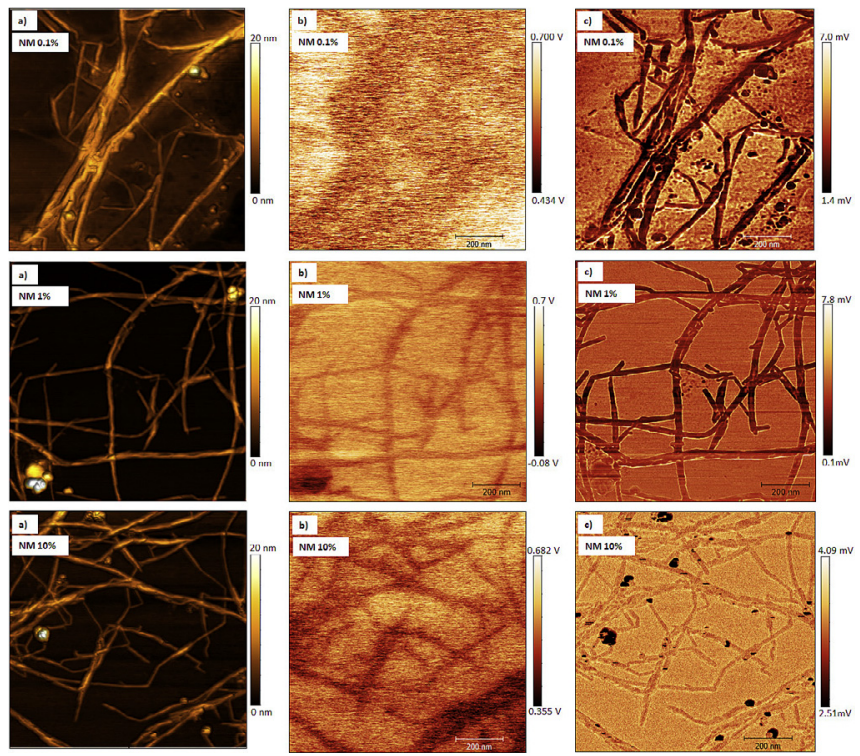

Fig. 5. AFM images from cellulose nanofibers obtained by acid hydrolysis with mechanical treatment: (a) topography, (b) electric potential and (c) dC/dz (scanning area $1.0 \mu \mathrm{m} \times 1.0 \mu \mathrm{m}$, scale bar $=200 \mathrm{~nm})$.

characteristics when they isolated nanofibers from cassava root bagasse and peelings and characterized them by the AFM and TEM techniques. The CNFs obtained in this work had average diameter ranging from 2.89 to $4.65 \mathrm{~nm}$ (Table 1), showing that the chemical and mechanical treatments effectively isolated cellulose fibers at the nanoscale. The CNF diameters had dimensions similar to the dimensions of nanosized structures derived from other sources such as nanofibers from banana rachis (4-5 nm) (Zuluaga et al., 2009) and smaller than the dimensions of nanofibers from banana peel bran (10.9-22.6 nm) (Pelissari et al., 2014) and rice straw (12-35 nm) and potato tuber (15-55 nm) (Abe \& Yano, 2009).

The KPFM measurements performed by AFM allowed us to achieve quantitative surface potential measurements with nanoscale resolution. The $\mathrm{dC} / \mathrm{dz}$ images (Figs. 5 and 6) helped us to identify the CNF domains-the high contrast between the darker and brighter domains indicated lower capacitance coupling, which resulted from lower local charge mobility in the sample. The smaller electric potential area values correlated with the low $\mathrm{dC} / \mathrm{dz}$ signal areas.

The peaks at 0.00414 and $0.00426 \mathrm{~V}$ (Fig. 6) showed $\mathrm{N} 0.1 \%$ and $\mathrm{N} 1 \%$ had higher capacitance coupling, respectively; i.e, these samples dissipated more charge on the surface as compared to the other samples. This pointed out that the low electric potential values as well as the capacitance coupling were related to the presence of cellulose. In contrast, NM $0.1 \%(0.002 \mathrm{~V})$ and NM $1 \%$ $(0.0021 \mathrm{~V})$ accumulated a higher amount of charges. According to Pelissari et al. (2014), mechanical treatment promotes electrostatic repulsion between the fibers, which provides enough surface charges to stabilize the CNF suspensions. The high-pressure homogenizer probably agitated the suspension more effectively and promoted greater contact between the components, which favored introduction of free sulfate groups from acid hydrolysis into the CNF surface. Remarkably, the opposite trend happened when the highest acid concentration was used to isolate the CNFs. NM 10\% became a more insulating material and dissipated more charge, whereas N 10\% accumulated a higher amount of charges when it incorporated a larger sulfate concentration (10\%).

As known, the nanofibers demonstrate a reinforcing potential as filler for composite materials. However, the use of such filler lies in 
Table 1

Results obtained for CNFs samples produced by chemical and mechanical treatments.

\begin{tabular}{|c|c|c|c|c|c|}
\hline Treatment & $\begin{array}{l}\text { Length, } L \\
(\mathrm{~nm})\end{array}$ & $\begin{array}{l}\text { Diameter, } d \\
(\mathrm{~nm})\end{array}$ & Aspect ratio, $L / d$ & $\begin{array}{l}\zeta \text {-potential } \\
(\mathrm{mV})\end{array}$ & $\begin{array}{l}\text { Yield } \\
(\%)\end{array}$ \\
\hline N $0.1 \%$ & $619.57 \pm 90.68^{c}$ & $4.65 \pm 2.30^{\mathrm{b}}$ & $133.21 \pm 19.50^{\mathrm{ac}}$ & $-44.77 \pm 0.90^{c}$ & $71.51 \pm 0.053^{c}$ \\
\hline N $1 \%$ & $559.10 \pm 48.50^{\mathrm{bc}}$ & $4.11 \pm 1.93^{\mathrm{ab}}$ & $136.20 \pm 11.81^{\mathrm{ac}}$ & $-51,87 \pm 0.21^{\mathrm{b}}$ & $62.06 \pm 0.005^{c}$ \\
\hline N $10 \%$ & $437.83 \pm 36.14^{\mathrm{ab}}$ & $3.72 \pm 1.50^{\mathrm{ab}}$ & $117.66 \pm 9.71^{\mathrm{abc}}$ & $-37.57 \pm 0.40^{\mathrm{d}}$ & $60.36 \pm 0.560^{c}$ \\
\hline NM $0.1 \%$ & $507.03 \pm 41.86^{\mathrm{bc}}$ & $3.53 \pm 1.38^{\mathrm{ab}}$ & $143.51 \pm 11.84^{\mathrm{c}}$ & $-67.37 \pm 0.66^{\mathrm{a}}$ & $43.38 \pm 0.008^{b}$ \\
\hline NM $1 \%$ & $326.33 \pm 27.14^{\mathrm{a}}$ & $3.47 \pm 1.19^{\mathrm{ab}}$ & $93.95 \pm 7.81^{\mathrm{a}}$ & $-67.00 \pm 0.96^{\mathrm{a}}$ & $37.31 \pm 0.005^{\mathrm{b}}$ \\
\hline NM $10 \%$ & $310.77 \pm 27.05^{a}$ & $2.89 \pm 0.81^{\mathrm{a}}$ & $107.25 \pm 9.33^{\mathrm{ab}}$ & $-53.20 \pm 0.61^{\mathrm{b}}$ & $27.07 \pm 0.023^{a}$ \\
\hline
\end{tabular}

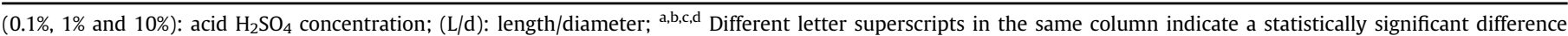
$(\mathrm{p}<0.05)$.

Table 2

Main bands of the FTIR spectra for the bran and CNFs.

\begin{tabular}{|c|c|c|c|c|}
\hline Sample & $\begin{array}{l}\text { Band region } \\
\left(\mathrm{cm}^{-1}\right)\end{array}$ & Assignment & Component & References \\
\hline $\begin{array}{l}\text { Bran and } \\
\text { CNFs }\end{array}$ & $\begin{array}{l}3650 \text { to } \\
3000\end{array}$ & -OH stretching & Water & $\begin{array}{l}\text { Andrade-Mahecha et al., 2015; Cherian et al., } \\
\text { 2008; Pelissari et al., } 2014\end{array}$ \\
\hline \multirow[t]{8}{*}{ Bran } & 2340 & -OH stretching & Cellulose II & Andrade-Mahecha et al., 2015 \\
\hline & 1730 & $\begin{array}{l}\text { Acetyl and uronic ester groups } \\
\text { vibration }\end{array}$ & $\begin{array}{l}\text { Lignin (hemicelluloses or ester linkage of carboxylic group of } \\
\text { the ferulic and } p \text { - coumaric acids) }\end{array}$ & Cherian et al., 2008 \\
\hline & 1612 & $\begin{array}{l}\text { Conjugated aromatic rings and } \\
\text { carbonyl stretching }\end{array}$ & Lignin & Hassan et al., 2010 \\
\hline & 1429 & C-H stretching & Lignin and waxes & Hassan et al., 2010 \\
\hline & $\begin{array}{l}1385 \text { and } \\
1285\end{array}$ & C-H deformation & Cellulose, hemicellulose and lignin & Pelissari et al., 2014; Zuluaga et al., 2009 \\
\hline & 1253 & $\mathrm{C}=\mathrm{O}$ stretching (guaiacyl ring) & Ester, ether, or phenol compounds & Siqueira et al., 2010 \\
\hline & 755 & $\mathrm{C}-\mathrm{H}$ stretching deformations & Lignin & W. Chen et al., 2011 \\
\hline & 850 & $\begin{array}{l}\text { Aromatic ring and } \mathrm{C}-\mathrm{H} \text { bonds } \\
\text { stretching }\end{array}$ & Lignin & W. Chen et al., 2011 \\
\hline \multirow[t]{3}{*}{ CNFs } & 2913 & $\mathrm{C}-\mathrm{H}$ stretching & Cellulose and hemicellulose & $\begin{array}{l}\text { Andrade-Mahecha et al., 2015; Cherian et al., } \\
\text { 2008; Pelissari et al., } 2014\end{array}$ \\
\hline & 1025 & $\begin{array}{l}\mathrm{C}-\mathrm{O}-\mathrm{C} \text { stretching vibration } \\
\text { (pyranose ring) }\end{array}$ & Cellulose & \\
\hline & 888 & C-H vibration & Cellulose & Hassan et al., 2010 \\
\hline
\end{tabular}
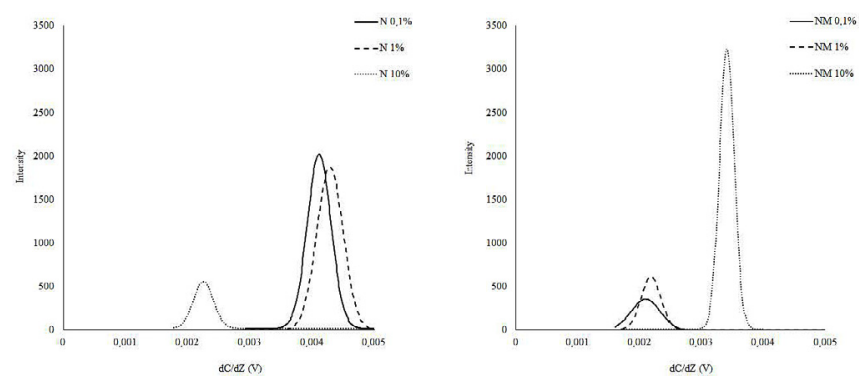

Fig. 6. Histogram distribution of the intensity of surface capacitance values over $1 \times 1$ $\mu \mathrm{m}$ sample of the cellulose nanofibers produced by acid hydrolysis and mechanical treatments (NM) and acid hydrolysis $(\mathrm{N})$. Acid concentration: $0.1,1$ and $10 \% \mathrm{of}_{2} \mathrm{H}_{4}$.

the difficulty in ensuring good dispersion of the filler in the composite material. The phenomenon of agglomeration of the CNFs in the matrix of a composite material seriously affects its mechanical properties. To overcome the dispersion issue and achieve a better compatibility in different matrices, studies have been carried out on surface modification of CNFs, whereby nanofibers are treated by various physical and chemical methods to decrease the energy consumption (Missoum, Belgacem, \& Bras, 2013). The main challenge for the functionalization of CNFs is to conduct the process so that the changes only occur on the surface of CNFs, while preserving the original morphology to avoid any polymorphic conversion and to maintain the integrity of the crystal (Islam, Alam, \& Zoccola, 2013). In this sense, KPFM measurements can help to provide more detailed results about the surface modification processes in order to expand the horizon of CNFs application.

Note that all the samples prepared in this study accumulated negative charge inside the fibers. This was easily identified because the darker and brighter edges showed negative charge accumulation (Figs. 4 and 5). The CNF electric potential values (Fig. 5B) were lower than the mica substrate electric potential values as seen by the darker color intensity. The electric potential difference between mica and the samples was around $50 \mathrm{mV}$, which was close to the values measured by the DLS technique (which ranged from -37.60 to $-67.37 \mathrm{mV}$ ). In this study all the CNF suspensions were deposited on mica substrate, which gave positive absolute values for the set (mica + sample). This happened because the mica substrate acted as insulator (not grounded), and the friction of the tip, the AC potential $(5 \mathrm{~V})$, or other environmental conditions may have generated a positive charge on the surface.

This could explain the different electric potential values obtained by DLS and KPFM. The KPFM technique showed how and where the charges accumulated on the CNF surface. However, performing other electric potential measurements with other equipment (e.g., DLS) is essential because various interferences stem from the equipment and from the sample characteristics (e.g., CNFs suspended in water or dried CNF suspension). That being so, KPFM and DLS analyses complemented one another.

$\zeta$-potential is a measure of colloidal suspension stability. Nanofiber suspensions with high $\zeta$-potential (absolute value) are electrically stable, whereas nanofiber suspensions with low $\zeta$-potentials tend to aggregate. Generally, particles with $\zeta$-potential higher than $+30 \mathrm{mV}$ or lower than $-30 \mathrm{mV}$ are considered kinetically stable (Driessche \& Hoste, 2006). Regarding the DLS 
measurements, all the CNF suspensions exhibited high and negative $\zeta$-potential values (Table 1). According to Pelissari et al. (2014), hydrolysis with $\mathrm{H}_{2} \mathrm{SO}_{4}$ causes electrostatic repulsion between nanofibers in suspensions because hydrolysis introduces natural sulfate groups into the nanofiber surface. NM $0.1 \%$ had the highest negative $\zeta$-potential value $(-67.37 \mathrm{mV})$; however, the values determined for NM $1 \%$ were not statistically different $(-67 \mathrm{mV}) . \mathrm{N}$ $10 \%$ presented the lowest negative $\zeta$-potential value, possibly due to the amount of free $\mathrm{H}^{+}$groups available in the medium, which may have reduced the overall negative charge on the nanofiber surface. Besides, high-pressure homogenization may have enhanced suspension homogenization and improved contact between the components, favoring introduction of free sulfate groups from acid hydrolysis into the nanofiber surface.

In aqueous suspension, fibers have negative charges mainly due to ionization of uronic groups (hexenuronic acids), which may be found in hemicelluloses and lignin (Foelkel, 2009). In our samples, increasing acid concentration may have removed charged groups, such as acid groups linked to xylan, the main component of hemicellulose (uronic and hexenuronic acids), to result in lower $\zeta$ potential (S.-L. Chen, Wang, \& Lucia, 2004).

The mechanical treatment also affected nanofiber surface charge positively: homogenization promoted electrostatic repulsion between the fibers, which provided enough surface charges to stabilize the suspension. Mechanically treated CNFs had the highest negative $\zeta$-potential values, which corresponded to more stable colloidal suspensions with less nanofiber aggregation. Highpressure homogenization can maximize repulsive forces between the nanofibers, giving rise to enough surface charges to stabilize the suspension.

Increasing acid concentration during the chemical treatment did alter nanofiber structure: CNF length decreased $(\mathrm{p}<0.05)$ (Table 1). The effect of the mechanical treatment on nanofiber morphology could be associated with fiber individualization, to culminate in a more separate network. The TEM and AFM images (Figs. 3 and 5) showed a large amount of filaments, demonstrating that the mechanical treatment not only individualized the nanofibers but also shortened them. Zuluaga, Putaux, Restrepo, Mondragon, and Gañán (2007) isolated CNFs from banana rachis and observed long and slender nanofibers, individualized or associated into bundles.

In general, the aspect ratio ranged from 93.95 to 143.51 (Table 1). The CNF aspect ratio has an important role in its performance as reinforcing material in polymeric matrixes because a high aspect ratio may favor tension transfer in the nanofiber-matrix interface (Andrade-Mahecha et al., 2015; W.; Chen et al., 2011; George, Ramana, Bawa, \& Siddaramaiah, 2011). According to Hongming, Zeng, Realff, Kumar, and Schiraldi (2003), to achieve significant composite reinforcement, CNFs should be ideally oriented and present aspect ratio greater than 100. In our study, the highest aspect ratio value was 143.51 (NM $0.1 \%$ ), which was statistically different $(p<0.05)$ from the aspect ratio of the samples treated with higher acid concentration (NM 1\% and NM 10\%). High acid concentration (1\% and $10 \%$ ) used in combination with the mechanical treatment broke the nanocellulose filaments into smaller sizes (length and diameter), consequently yielding smaller aspect ratio. The samples without mechanical treatment $(\mathrm{N} 0.1 \%, \mathrm{~N}$ $1 \%$, and $\mathrm{N} 10 \%$ ) did not have significantly different aspect ratio $(\mathrm{p}>0.05)$.

The CNF yield decreased when the acid concentration used during hydrolysis increased (Table 1), probably because higher acid concentration removed more amorphous compounds. Also, the mechanical treatment reduced CNF yield further. According to the XRD results (mentioned below), the mechanical treatment removed part of the CNF amorphous portion. Moreover, the mechanical treatment meant that extra steps had to be performed, which probably caused greater sample loss. N samples (acid hydrolysis treatment) and NM samples (acid hydrolysis combined with mechanical treatment) had statistically different yields.

XRD analysis were conducted to investigate how the chemical treatment affected the CNF crystalline nature. The crystallinity index is related to the large number of secondary molecular bonds in the crystalline regions and to the level of compaction in these regions (Andrade-Mahecha et al., 2015). Fig. 7 illustrates the XRD patterns of the untreated cellulose fibers (bran) and of the CNFs prepared in this study. All the prepared CNFs presented similar diffraction patterns, with two main reflection peaks at $2 \theta=16^{\circ}$ and $2 \theta=22^{\circ}$ (typical of cellulose I), which indicated higher CNF crystallinity as compared to bran fibers. The X-ray diffraction pattern revealed that the bran contained a large amorphous portion. The typical B-type pattern peak at $2 \theta=17^{\circ}$ evidenced the presence of starch (Pelissari et al., 2014). The CNF crystallinity index (Icr) was $65.8,66.2,66.4,55.5,60.4$, and $62.1 \%$ for NM $0.1 \%$, NM $1 \%$, NM $10 \%$, $\mathrm{N} 0,1 \%, \mathrm{~N} 1 \%$, and $\mathrm{N} 10 \%$, respectively. Compared to the initial bran sample $(\mathrm{Icr}=12.1 \%)$, the degree of crystallinity increased after each treatment step. After alkaline treatment, the bran sample had Icr $=36.55 \%$, which went up to $37.45 \%$ after bleaching. The final CNF crystallinity increased by approximately $450 \%$ compared to the initial bran. On the basis of the results, the chemical treatment preferentially acted in the amorphous region and effectively extracted amorphous components present in the banana peel waste. The largest acid concentration $\left(10 \% \mathrm{H}_{2} \mathrm{SO}_{4}\right)$ facilitated removal of amorphous compounds and increased the crystalline area. The mechanical treatment also affected the CNF degree of crystallinity because it removed part of the CNF amorphous portion. These results are support by the yield calculations, where the lowest yields were reported in the samples obtained with the largest acid concentration that underwent mechanical treatment. Both factors favored the greater removal of the amorphous components, which culminated in higher crystallinity indexes.

Mulberry branch bark nanofibers obtained by acid hydrolysis had Icr of $58.8 \%$ (Li et al., 2009), which was similar to the value found for the CNFs after acid hydrolysis herein. Pelissari et al. (2014) verified that chemical and mechanical treatments affect the CNF degree of crystallinity when they examined the effect of the highpressure homogenizer and of the number of passages on the nanofiber structure. These authors obtained CNFs with Icr values ranging from 58.6 (without mechanical treatment) to $64.9 \%$ (with seven passages) under pressure of 500 and 50 bar in the first and

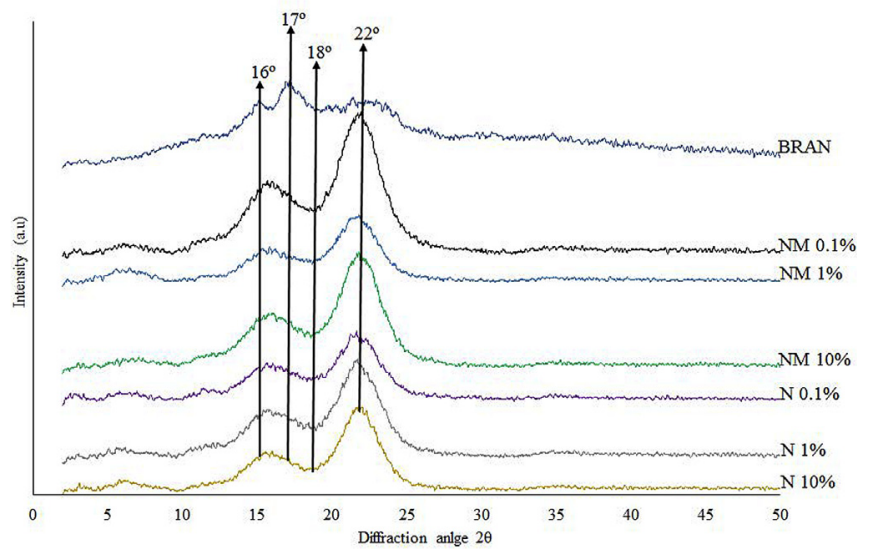

Fig. 7. X-ray diffraction patterns of the banana peel bran, cellulose nanofibers obtained by chemical treatment $(\mathrm{N} 0.1 \%, \mathrm{~N} 1 \%$ and $\mathrm{N} 10 \%)$ and combination of chemical and mechanical treatments (NM 0.1\%, NM 1\% and NM 10\%). 
second stages, respectively. Therefore, mechanical treatment raises the CNF crystallinity index.

CNFs samples were analyzed by FTIR to determine their chemical structure. Fig. 8 depicts the FTIR spectra of the untreated cellulose fibers (bran) and of the CNFs isolated by the chemical and mechanical treatments. Table 2 lists the main FTIR bands observed in the FTIR spectra of the bran and CNFs as well as their assignments. The band near $1253 \mathrm{~cm}^{-1}$ ( $\mathrm{C}=\mathrm{O}$ stretching of the guaiacyl ring) in the spectrum of the banana peel bran became less intense in the spectrum of the bran submitted to alkaline treatment and bleaching and disappeared in the spectrum of the CNFs obtained after acid hydrolysis. This band is typical of ester, ether, or phenol compounds bearing = CO- groups (Siqueira, Bras, \& Dufresne, 2010). All the CNFs presented similar spectral patterns. After the chemical treatment, the band at $1429 \mathrm{~cm}^{-1}$ became slightly less intense for the CNFs because lignin was partially eliminated. The bran spectrum displayed peaks in the $1612 \mathrm{~cm}^{-1}$ region, which became less intense for the CNFs. This could indicate partial removal of the conjugated aromatic rings and carbonyl groups present in the polyphenolic structure of lignin (Hassan, Mathew, Hassan, \& Oksman, 2010) during the chemical treatment. The peak at $1730 \mathrm{~cm}^{-1}$ became less intense after the chemical treatment because the chemical process dissolved the bran hemicellulose and lignin components. In addition, Fig. 8 demonstrated that bleaching removed most lignin from the CNFs; indeed, the peaks at $755 \mathrm{~cm}^{-1}$ (C-H deformations) and $850 \mathrm{~cm}^{-1}$ (aromatic ring and C$\mathrm{H}$ bonds) became less intense after the chemical treatment (W. Chen et al., 2011).

\subsection{Cellulose nanofiber cytotoxicity}

Since nanofibers have considerable potential for future foodrelated applications, additional work is necessary to obtain further information about their toxicological characteristics and their possible impact on human health. Caco-2 line cell was exposed to different CNF concentrations for $24 \mathrm{~h}$ and monitored cell viability by the MTT assay. Fig. 9 displays the concentrationdependent effects of the CNFs produced by chemical and mechanical treatments on Caco-2 cell viability.

In general, Caco-2 cell viability decreased slightly with increasing CNF concentration (Fig. 9). Compared to the positive control group (cell viability $=100 \%$ ), the percentage of live cells was not significantly affected (from a statistical viewpoint, $\mathrm{p} \geq 0.05$ ) after exposure of the cells to all the CNF samples at concentrations of 50 (94.9\%), 100 (91.15\%), and $500 \mu \mathrm{g} / \mathrm{mL}$ (91.41\%). Cell viability reduced significantly $(\mathrm{p} \leq 0.05)$ upon contact with $\mathrm{N} 1 \%(81.66 \%)$,

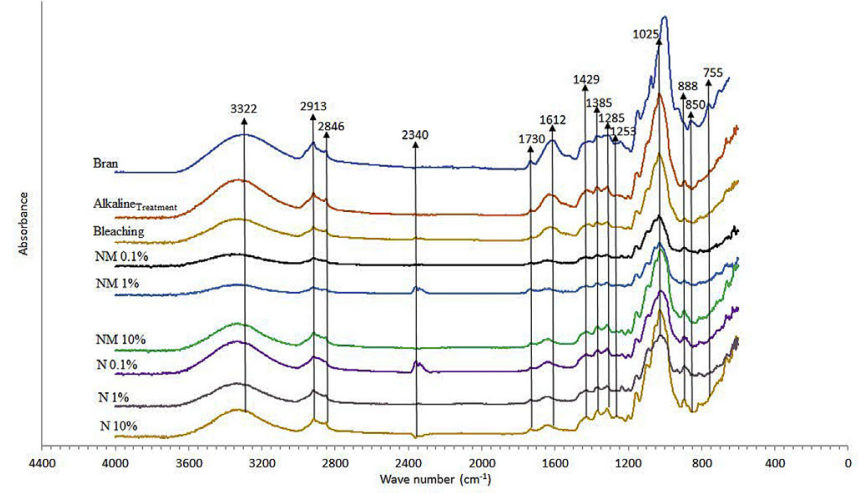

Fig. 8. FTIR spectra of the banana peel bran, alkaline treatment sample, bleaching treatment sample, cellulose nanofibers obtained by chemical treatment ( $\mathrm{N} 0.1 \%, \mathrm{~N} 1 \%$ and $\mathrm{N} \mathrm{10 \% )} \mathrm{and} \mathrm{chemical} \mathrm{and} \mathrm{mechanical} \mathrm{treatments} \mathrm{(NM} \mathrm{0.1 \% ,} \mathrm{NM} \mathrm{1 \%} \mathrm{and} \mathrm{NM} \mathrm{10 \% ).}$

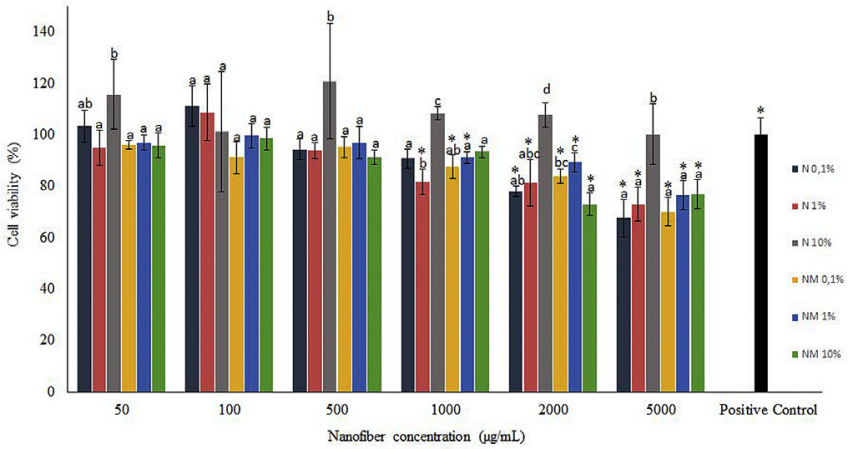

Fig. 9. Effect of CNFs produced by chemical and mechanical treatments on Caco- 2 cell viability after $24 \mathrm{~h}$ of incubation, at 0 (positive control group), $50-5000 \mu \mathrm{g} / \mathrm{mL}$ of CNFs (bars represent standard deviation). ${ }^{a, b, c, d}$ Different letter superscripts in the same concentration indicate a statistically significant difference between samples $(p<0.05)$. * Asterisks denote a significant difference relative to the positive control group $(\mathrm{p}<0.05)$.

NM $0.1 \%$ (87.45\%), and NM 1\% (91.23\%) at $1000 \mu \mathrm{g} / \mathrm{mL}$. At this concentration, the other CNF samples did not decrease cell viability significantly as compared to the positive control group ( $\mathrm{p} \geq 0.05$ ). CNF concentrations higher than $2000 \mu \mathrm{g} / \mathrm{mL}$ were cytotoxic to Caco-2 cells; the exception was N 10\%, which was not cytotoxic at any of the tested concentrations. The use of such high CNF concentrations during reinforced biodegradable film production is not expected. Furthermore, once CNFs are incorporated into biodegradable films, they will presumably be unable to migrate out of the film structure, thereby posing virtually no danger to consumers or the environment. In any case, evaluation of final material safety (i.e., regarding CNF migration) should be performed in future works.

For all CNFs, $500 \mu \mathrm{g} / \mathrm{mL}$ is the highest concentration that can be used without impairing cell viability. Cell exposure to increased CNF concentration probably increased CNF cellular uptake, which may have saturated lysosomes, generated reactive oxygen species (ROS), damaged DNA cells, and injured membrane or endosomal compartments as reported by Pereira et al. (2013). Additionally, CNFs differed significantly in terms of size, length, diameter, aspect ratio, and other characteristics arising from the nanofiber synthesis process. Correlation between these parameters and cytotoxicity results could explain the effects of the different CNF samples prepared herein on cell viability.

Caco- 2 cells presented higher viability (around 100\%) when they were placed in contact with $\mathrm{N} 10 \%$ at concentrations ranging from 500 to $5000 \mu \mathrm{g} / \mathrm{mL}$, with statistical differences from the other samples $(\mathrm{p} \leq 0.05)$. These results suggested that higher acid concentration (10\%) and a higher amount of removed residues (lignin and hemicellulose) favored cell proliferation. According to Villanova et al. (2011), cellulose may serve as substrate for cell growth. Xu, Liu, Wei, and Sun (2012) hypothesized that the toxicity of different nanoparticles may stem from particle shapes. Needleshaped and short rod-like particles induce greater cellular injury than spherical and long rod-like particles. However, carbon nanotubes, nanomaterials with practically the same shape as CNFs, can be toxic to cells. Male, Leung, Montes, Kamen, and Luong (2012) showed that cellulose nanowhiskers (220 nm $\times 15 \mathrm{~nm}$ ) prepared from cotton have very low cytotoxicity and pro-inflammatory activity. Pereira et al. (2013) obtained a nanoparticle with the same needle-like shape of the CNFs produced in this study and found that cotton CNFs at concentrations above $200 \mu \mathrm{g} / \mathrm{mL}$ are toxic to fibroblast cells cultured in vitro. According to these authors, high CNF concentrations (2000 and $5000 \mu \mathrm{g} / \mathrm{mL}$ ) could damage the cell 
membrane and interfere with compartmentalization and expression of stress- and apoptosis-transcripts in fibroblasts cells, increasing cell death. The $\zeta$-potential is a critical parameter that determines nanoparticle stability or aggregation in dispersion. In this study, $\mathrm{N} 10 \%$ had the lowest negative $\zeta$-potential value, $-37.57 \mathrm{mV}$ (Table 1 ), and it tended to agglomerate, especially in highly concentrated aqueous solutions. Compared to individualized fibers, agglomerated nanofibers may cause different effects on cells, which could help to explain the different responses obtained herein for the different CNF samples. According to de Lima et al. (2012), aggregation of CNFs from different sources (e.g., green, white, and brown cotton and curaua) reduces cell cytotoxicity to Allium cepa roots and animal cell cultures (lymphocytes and fibroblasts). Nevertheless, Pereira et al. (2013) showed that higher cotton CNF concentrations result in large CNF aggregates and alter the gene expression of cells, which could induce cell cytotoxicity. Further studies are necessary for better understanding of the influence of nanofiber aggregation on cell viability.

Considering the potential CNF cytotoxicity is important because $\mathrm{CNFs}$ are intended for use as reinforcement agents in polymeric matrixes, where even low CNF concentrations can improve thermal stability, mechanical resistance, and permeability to liquids and gases. In their intact state, polymeric matrixes are unlikely to release nanofibers. At concentrations lower than $500 \mu \mathrm{g} / \mathrm{mL}$, CNFs obtained by chemical treatment of banana peel bran were not cytotoxic to Caco-2 cells. This warrants the development and promotion of this renewable nanomaterial for a wide variety of industrial applications.

\section{Conclusion}

Alkaline treatment and bleaching of banana peel bran removes large amounts of amorphous compounds and affords cellulose as the main isolated component. Acid hydrolysis combined with mechanical treatment (i.e., high-pressure homogenization) effectively produces nanometric cellulose fibers. On the basis of surface evaluation, the fibers undergo morphological changes along the chemical treatment steps. TEM and AFM analyses confirmed that cellulose nanofibers are present in all the treated samples. The treated banana fiber crystallinity is $300 \%$ higher as compared to the initial bran. FTIR spectra attested that the treatments effectively remove most hemicellulose and lignin components. All the cellulose nanofibers have negative $\zeta$-potential values. The NM $0.1 \%$ sample presents the highest negative $\zeta$-potential value $(-67.37 \mathrm{mV})$, which makes it a potential reinforcing agent in polymer matrixes. The MTT assay demonstrated that, at concentrations ranging from 1000 to $5000 \mu \mathrm{g} / \mathrm{mL}$, the cellulose nanofiber samples prepared from banana peel bran are cytotoxic to the tested cell line to a certain extent. Cellulose nanofiber concentrations of up to $500 \mu \mathrm{g} / \mathrm{mL}$ are not cytotoxic to Caco-2 cells and can be safely used. However, it is still essential to study the possible effects of cellulose nanofibers to the human health in vivo because nanoparticles migration can migrate from packaging materials to food products. Overall, the toxicological analysis of cellulose nanofibers isolated by chemical and mechanical treatments shows the innovative character of this research. Cellulose nanofibers were successfully isolated from banana peels, an agroindustrial waste, and the resulting fibers have features that point to their potential application as reinforcement material in composites.

\section{Acknowledgments}

The authors would like to acknowledge the financial support provided by Coordenação de Aperfeiçoamento de Pessoal de Nível Superior (2952/2011), Conselho Nacional de Desenvolvimento
Científico e Tecnológico (150523/2013-0 and 140274/2014-6), and CAPES/FCT 349/13 for the PhD exchange program. Joana T. Martins acknowledges the Foundation for Science and Technology for her fellowship (SFRH/BPD/89992/2012). This study was supported by FCT under the scope of the strategic funding of UID/BIO/04469/ 2013 unit and COMPETE 2020 (POCI-01-0145-FEDER-006684) and BioTecNorte operation (NORTE-01-0145-FEDER-000004) funded by the European Regional Development Fund under the scope of Norte2020 - Programa Operacional Regional do Norte. This study was also supported by FCT under the scope of the Project RECI/BBBEBI/0179/2012 (FCOMP-01-0124-FEDER-027462). The authors would also like to acknowledge the Brazilian Nanotechnology National Laboratory (LNNano) for allocation of the TEM and AFM apparatus.

\section{References}

Abe, K., \& Yano, H. (2009). Comparison of the characteristics of cellulose microfibril aggregates of wood, rice straw and potato tuber. Cellulose, 16(6), 1017-1023.

Andrade-Mahecha, M. M., Pelissari, F. M., Tapia-Blácido, D. R., \& Menegalli, F. C. (2015). Achira as a source of biodegradable materials: Isolation and characterization of nanofibers. Carbohydrate Polymers, 123, 406-415.

Antunes, F., Andrade, F., Araujo, F., Ferreira, D., \& Sarmento, B. (2013). Establishment of a triple co-culture in vitro cell models to study intestinal absorption of peptide drugs. European Journal of Pharmaceutics and Biopharmaceutics, 83(3), 427-435.

Araújo, F., \& Sarmento, B. (2013). Towards the characterization of an in vitro triple co-culture intestine cell model for permeability studies. International Journal of Pharmaceutics, 458(1), 128-134.

Chen, D., Lawton, D., Thompson, M. R., \& Liu, Q. (2012). Biocomposites reinforced with cellulose nanocrystals derived from potato peel waste. Carbohydrate Polymers, 90(1), 709-716.

Chen, S.-L., Wang, S., \& Lucia, L. A. (2004). New insights into the fundamental nature of lignocellulosic fiber surface charge. Journal of Colloid and Interface Science, 275(2), 392-397.

Chen, W., Yu, H., Liu, Y., Hai, Y., Zhang, M., \& Chen, P. (2011). Isolation and characterization of cellulose nanofibers from four plant cellulose fibers using a chemical-ultrasonic process. Cellulose, 18(2), 433-442.

Cherian, B. M., Pothan, L. A., Nguyen-Chung, T., Mennig, G., Kottaisamy, M., \& Thomas, S. (2008). A novel method for the synthesis of cellulose nanofibril whiskers from banana fibers and characterization. Journal of Agricultural and Food Chemistry, 56(14), 5617-5627.

Dong, S., Hirani, A. A., Colacino, K. R., Lee, Y. W., \& Roman, M. (2012). Cytotoxicity and cellular uptake of cellulose nanocrystals. Nano LIFE, 2(03), 1241006.

Driessche, I. V., \& Hoste, S. (2006). Encapsulations through the sol-gel technique and their applications in functional coatings. In S. K. Ghosh (Ed.), Functional coatings: By polymer microencapsulation (pp. 259-269). Zelzate, Belgium: Wiley-VCH Verlag GmbH \& Co. KGaA.

Dufresne, A., Cavaille, J. Y., \& Vignon, M. (1997). Mechanical behavior of sheets prepared from sugar beet cellulose microfibrils. Journal of Applied Polymer Science, 1185-1194.

Dufresne, A., \& Vignon, M. (1998). Improvement of starch film performances using cellulose microfibrils. Macromolecules, 31(8), 2693-2696.

Elanthikkal, S., Gopalakrishnapanicker, U., Varghese, S., \& Guthrie, J. T. (2010). Cellulose microfibres produced from banana plant wastes: Isolation and characterization. Carbohydrate Polymers, 80(3), 852-859.

Ferreira, E. S., Lanzoni, E. M., Costa, C. A. R., Deneke, C., Bernardes, J. S., \& Galembeck, F. (2015). Adhesive and reinforcing properties of soluble cellulose: A repulpable adhesive for wet and dry cellulosic substrates. ACS Applied Materials \& Interfaces, 7(33), 18750-18758.

Foelkel, C. (2009). Diferenciando polpas de mercado e papéis de eucalipto através da gestão de finos celulósicos da polpa Accessed in: 10.03.2017 http://www eucalyptus.com.br/eucaliptos/PT17_Finoscelulosicos.pdf/.

George, J., Ramana, K. V., Bawa, A. S., \& Siddaramaiah. (2011). Bacterial cellulose nanocrystals exhibiting high thermal stability and their polymer nanocomposites. International Journal of Biological Macromolecules, 48(1), 50-57.

Hassan, M., Mathew, A., Hassan, E., \& Oksman, K. (2010). Effect of pretreatment of bagasse pulp on properties of isolated nanofibers and nanopaper sheets. Wood and Fiber Science, 42(3), 362-376.

Hongming, M., Zeng, J., Realff, M. L., Kumar, S., \& Schiraldi, D. A. (2003). Processing, structure, and properties of fibers from polyester/carbon nanofiber composites. Composites Science and Technology, 63(11), 1617-1628.

Islam, Mohammad Tajul, Alam, Mohammad Mahbubul, \& Zoccola, Marina (2013). Review on modification of nanocellulose for application in composites. International Journal for Innovative Research in Science \& Technology, 2(10), 5444-5451.

Jiang, F., \& Hsieh, Y.-L. (2015). Cellulose nanocrystal isolation from tomato peels and assembled nanofibers. Carbohydrate Polymers, 122, 60-68.

Jiménez, A., Fabra, M. J., Talens, P., \& Chiralt, A. (2012). Edible and biodegradable starch films: A review. Food and Bioprocess Technology, 5(6), 2058-2076. 
Jones, C. F., \& Grainger, D. W. (2009). In vitro assessments of nanomaterial toxicity. Advanced Drug Delivery Reviews, 61(6), 438-456.

Lavoine, N., Desloges, I., Dufresne, A., \& Bras, J. (2012). Microfibrillated cellulose-its barrier properties and applications in cellulosic materials: A review. Carbohydrate Polymers, 90(2), 735-764.

Leite, A. L. M. P., Zanon, C. D., \& Menegalli, F. C. (2017). Isolation and characterization of cellulose nanofibers from cassava root bagasse and peelings. Carbohydrate Polymers, 157, 962-970.

Li, R., Fei, J., Cai, Y., Li, Y., Feng, J., \& Yao, J. (2009). Cellulose whiskers extracted from mulberry: A novel biomass production. Carbohydrate Polymers, 76(1), 94-99.

de Lima, R., Oliveira Feitosa, L., Rodrigues Maruyama, C., Abreu Barga, M. Yamawaki, P. C., Vieira, I. J., et al. (2012). Evaluation of the genotoxicity of cellulose nanofibers. International Journal of Nanomedicine, 7, 3555-3565.

Ma, J., Guan, R., Shen, H., Lu, F., Xiao, C., Liu, M., et al. (2013). Comparison of anticancer activity between lactoferrin nanoliposome and lactoferrin in Caco-2 cells in vitro. Food and Chemical Toxicology, 59(0), 72-77.

Male, K. B., Leung, A. C., Montes, J., Kamen, A., \& Luong, J. H. (2012). Probing inhibitory effects of nanocrystalline cellulose: Inhibition versus surface charge. Nanoscale, 4(4), 1373-1379.

Mali, S., Grossmann, M. V. E., \& Yamashita, F. (2010). Starch films: Production, properties and potential of use. Semina: Agricultural sciences, 31, 137-156.

Missoum, K., Belgacem, M. N., \& Bras, J. (2013). Nanofibrillated cellulose surface modification: A review. Materials, 6(5), 1745-1766.

Pelissari, F. M., Andrade-Mahecha, M. M., Sobral, P. J. d. A., \& Menegalli, F. C. (2017) Nanocomposites based on banana starch reinforced with cellulose nanofibers isolated from banana peels. Journal of Colloid and Interface Science, 505, 154-167.

Pelissari, F., Sobral, P. A., \& Menegalli, F. (2014). Isolation and characterization of cellulose nanofibers from banana peels. Cellulose, 21(1), 417-432.

Pereira, M. M., Raposo, N. R., Brayner, R., Teixeira, E. M., Oliveira, V., Quintao, C. C. et al. (2013). Cytotoxicity and expression of genes involved in the cellular stress response and apoptosis in mammalian fibroblast exposed to cotton cellulose nanofibers. Nanotechnology, 24, 075103.

Pirani, S., \& Hashaikeh, R. (2013). Nanocrystalline cellulose extraction process and utilization of the byproduct for biofuels production. Carbohydrate Polymers, 93(1), 357-363.

Saito, T., Hirota, M., Tamura, N., Kimura, S., Fukuzumi, H., Heux, L., et al. (2009).
Individualization of nano-sized plant cellulose fibrils by direct surface carboxylation using TEMPO catalyst under neutral conditions. Biomacromolecules, 10(7), 1992-1996.

Segal, L., Creely, J. J., Martin, A. E., \& Conrad, C. M. (1959). An empirical method for estimating the degree of crystallinity of native cellulose using the x-ray diffractometer. Textile Research Journal, 29, 786-794.

Siqueira, G., Bras, J., \& Dufresne, A. (2010). Luffa cylindrica as a lignocellulosic source of fiber, microfibrillated cellulose, and cellulose nanocrystals. BioResources, 5(2), $727-740$.

Sun, J. X., Sun, X. F., Zhao, H., \& Sun, R. C. (2004). Isolation and characterization of cellulose from sugarcane bagasse. Polymer Degradation and Stability, 84(2), 331-339.

Van Soest, J. J. G., Hulleman, S. H. D., de Wit, D., \& Vliegenthart, J. F. G. (1996). Changes in the mechanical properties of thermoplastic potato starch in relation with changes in B-type crystallinity. Carbohydrate Polymers, 29(3), 225-232.

Vicentini, N. M., Dupuy, N., Leitzelman, M., Cereda, M. P., \& Sobral, P. J. A. (2005). Prediction of cassava starch edible film properties by chemometric analysis of infrared spectra. Spectroscopy Letters, 38(6), 749-767.

Viikari, L., Kantelinen, A., Sundquist, J., \& Linko, M. (1994). Xylanases in bleaching: From an idea to the industry. FEMS Microbiology Reviews, 13(2-3), 335-350.

Villanova, J., Ayres, E., Carvalho, S., Patrício, P., Pereira, F., \& Oréfice, R. (2011). Pharmaceutical acrylic beads obtained by suspension polymerization containing cellulose nanowhiskers as excipient for drug delivery. European Journal of Pharmaceutical Sciences, 42(4), 406-415.

Xu, Z., Liu, C., Wei, J., \& Sun, J. (2012). Effects of four types of hydroxyapatite nanoparticles with different nanocrystal morphologies and sizes on apoptosis in rat osteoblasts. Journal of Applied Toxicology, 32(6), 429-435.

Yu, Y., Lou, X., \& Wu, H. (2008). Some recent advances in hydrolysis of biomass in hot-compressed water and its comparisons with other hydrolysis methods. Energy and Fuels, 22(1), 46-60.

Zuluaga, R., Putaux, J. L., Cruz, J., Vélez, J., Mondragon, I., \& Gañán, P. (2009). Cellulose microfibrils from banana rachis: Effect of alkaline treatments on structural and morphological features. Carbohydrate Polymers, 76(1), 51-59.

Zuluaga, R., Putaux, J.-L., Restrepo, A., Mondragon, I., \& Gañán, P. (2007). Cellulose microfibrils from banana farming residues: Isolation and characterization. Cellulose, 14(6), 585-592. 